\title{
High Energy Density “Bezel-less" Lithium-ion Battery Using Solvate lonic Liquid-based Quasi-solid-state Electrolyte
}

\section{Atsushi UNEMOTO,* Motoyuki HIROOKA, Eiji SEKI, Jun KAWAJI, and Takefumi OKUMURA}

Research \& Development Group, HITACHI, Ltd., 7-1-1 Omika, Hitachi, Ibaraki 319-1292, Japan

*Corresponding author: atsushi.unemoto.zt@hitachi.com

\section{ABSTRACT}

We propose a novel "bezel-less" lithium-ion battery (LIB) structure that enhances the volumetric energy density of LIB. This structure reduces the extra-space volume for seal and accumulation of current collectors, eliminating the bezel part by $16 \%$ compared to the conventional aluminum laminated LIBs. The bezel-less LIB using a Ni-rich positive electrode and a graphite negative electrode recorded an energy of $132 \mathrm{Wh}$ and high energy density of $600 \mathrm{Wh} \mathrm{L}^{-1}\left(256 \mathrm{Wh} \mathrm{kg}^{-1}\right)$. The safety of the proposed bezel-less LIB by a combined use of the quasi-solid-state electrolyte layer was successfully demonstrated in overcharge and collapse tests.

(C) The Author(s) 2020. Published by ECSJ. This is an open access article distributed under the terms of the Creative Commons Attribution 4.0 License (CC BY, http://creativecommons.org/licenses/by/4.0/), which permits unrestricted reuse of the work in any medium provided the original work is properly cited. [DOI: 10.5796/electrochemistry.19-00076]. Uploading "PDF file created by publishers" to institutional repositories or public websites is not permitted by the copyright license agreement.

Keywords : High Capacity, High Energy Density, Quasi-solid-state Electrolyte, Safety

\section{Introduction}

Lithium ion batteries (LIBs) are currently used in a wide range of applications, offering a higher energy density than other electrochemical energy storage devices. For large-scale applications including electric vehicles (EVs), distributed power supply for highly efficient use of renewable energy resources and so forth, further increase of energy density is urgently needed. To meet these requirements, efforts are made in $R \& D$ of electrode materials to pair high-capacity positive electrodes (Ni-rich type, Li-rich type, ${ }^{1}$ sulfurbased conversion positive electrodes, ${ }^{2}$ etc.) and negative electrodes (silicon, ${ }^{3}$ Li-metal, ${ }^{4}$ etc.). One of the challenges for practical applications is enhancing the cycle life of batteries, which is compromised by the formation of high resistive layers, destabilization of the crystal structures, dissolution into electrolyte liquid, collapse of the microstructure accompanied by repeated volume expansion and shrinkage, dendrite growth, etc.

Another possible approach to enhance the energy density of LIBs for large-scale applications such as EVs is by improving its safety. Conventional organic liquid electrolyte solvents used for LIBs have high vapor pressure and are inflammable, so LIBs can catch fire and explode if unexpected accidents occur. ${ }^{5}$ Hence, current rechargeable systems, namely the battery packs, require a safety system and a cooling space, which do not contribute to energy storage but reduce the energy density of the LIB packs. If the constituent materials of LIBs can be enhanced, such safety systems and cooling spaces will become unnecessary and could be removed, thus improving the battery pack efficiency (the ratio of the LIB volume to the overall LIB pack volume) and the energy density of the LIB packs. ${ }^{6}$

On the basis of this LIB pack design principle, we developed a quasi-solid-state electrolyte (QSE) comprised of a solvate ionic liquid and silica particles. ${ }^{6}$ In our preceding study, an equimolar complex of G4 and LiTFSA, Li(G4)TFSA, developed by Watanabe and his co-workers was used for the solvate ionic liquid. ${ }^{7,8}$ Owing to a strong interaction between the solvate ionic liquid and the oxide particle surfaces, the resultant QSE possesses solid-like mechanical toughness and liquid-like ionic conductivity. ${ }^{9,10}$ High safety of a 100 Wh-class laminated LIB with the QSE was successfully demonstrated by a nail penetration test, where a thermal runaway was inhibited. A $10-\mathrm{kWh}$ battery pack built with the developed 100 Wh-class laminated LIB allowed driving a compact EV. ${ }^{6}$

Apart from the enhancing LIB pack energy density with a highly safe QSE, ${ }^{6}$ there is also a possibility of improving the battery design to increase the energy density of the LIB itself. In this communication, we propose a bezel-less LIB that eliminates the extra space needed for casing, as shown in Figs. 1(a) and (b). The idea of the bezel-less structure comes from the smartphone displays with extremely narrow casing, which gives users an impression that the product does not have the bezel part. ${ }^{11}$ By switching from the conventional aluminum laminate to the bezel-less structure as shown in Figs. 1(c) and (d), we reduced the LIB cell volume by $16 \%$ (see the detail of the calculation in Supporting Information). By combining a Ni-rich high capacity positive electrode, a graphite negative electrode and the QSE, the proposed structure has successfully demonstrated high energy density of $600 \mathrm{WhL}^{-1}$ (defined by the LIB volume) and high capacity of $132 \mathrm{Wh}$. High safety of the bezel-less LIB was demonstrated by overcharge and collapse tests, which are parts of the International Electrotechnical Commission (IEC) standards, IEC62660-3.

\section{Experimental}

Commercially available $\mathrm{LiNi}_{0.8} \mathrm{Co}_{0.1} \mathrm{Mn}_{0.1} \mathrm{O}_{2}$ (GELON LIB GROUP, denoted by NCM hereafter) with a $20-\mu \mathrm{m}$ grain diameter was used for the active material of the positive electrode. A positive electrode slurry was prepared by mixing NCM with acetylene black as a conductive additive (HS-100, Denka Company Ltd.), polyvinylidene difluoride (PVdF, KF polymer \#9708, Kureha Corp.) as a binder, and N-methylpyrollidone (NMP) at the desired ratio. The weight ratio of NCM, conductive additive and a binder was $96: 2: 2$. The resultant slurry was painted on both surfaces of a $15-\mu \mathrm{m}$ thick aluminum foil current collector, dried, pressed, and then used for the composite positive electrode. The weight of the bi-side positive electrode layers was $53 \mathrm{mg} \mathrm{cm}^{-2}$, and the thickness and the density were $88 \mu \mathrm{m}$ and $3.0 \mathrm{~g} \mathrm{~cm}^{-3}$, respectively. Natural graphite was used for the negative electrode active material, which was mixed with styrene-butadiene rubber (SBR) and carboxymethyl cellulose (CMC, 2200, Dicel FineChem, Ltd.) in water. The weight 

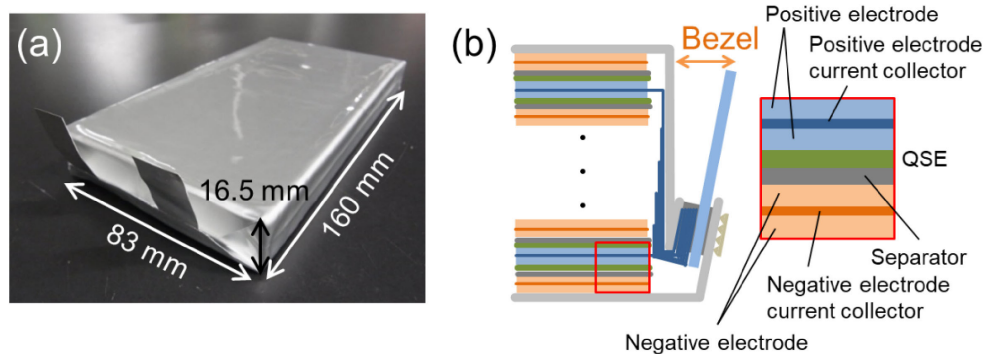

(c)

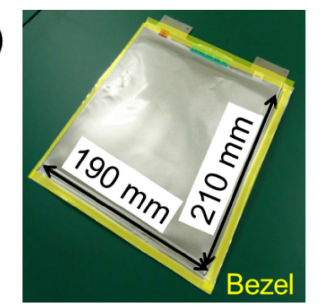

Thickness: $10 \mathrm{~mm}$ (d)

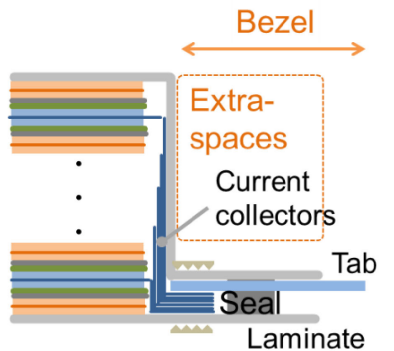

(e)
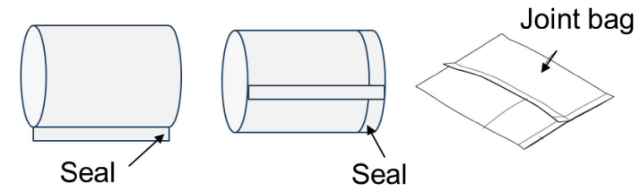

Figure 1. (a) Photograph and (b) cross-sectional illustration of the bezel-less LIB. (c) Photograph and (d) cross-sectional illustration of a conventional laminated LIB. ${ }^{6}$ Yellow part in (c) shows the bezel part, i.e. space for sealing and accumulation of current collectors. (e) Joint bag preparation procedure for use in bezel-less LIB.

ratio of graphite, SBR and CMC was 98:1:1. The resultant slurry was coated on both surfaces of an 8 - $\mu \mathrm{m}$ thick copper current collector, dried, pressed, and then used for the negative electrode. The weight of the bi-side negative electrode coating was $28 \mathrm{mg} \mathrm{cm}^{-2}$, and the thickness and the density were $88 \mu \mathrm{m}$ and $1.6 \mathrm{~g} \mathrm{~cm}^{-3}$, respectively.

To reduce the thickness of the QSE and the electrolyte resistance of the assembled cells, the QSE slurries comprised of silica, poly(vinylidene fluoride hexafluoropropylene) (P(VdF-HFP), KF polymer \#8500, Kureha Corp.) as a binder and NMP were coated on the positive electrode with a $10-\mu \mathrm{m}$ thickness. Cross-sectional image was observed for the bi-layer QSE and positive electrode. The crosssection was prepared by using an ion-milling equipment (Hitachi High-Technologies Corp.) with an acceleration voltage of $6 \mathrm{kV}$ for $2 \mathrm{~h}$. Then, field-emission scanning electron microscopy (FE-SEM, S-4300, Hitachi, Ltd.) observation was carried out for the processed cross-section with an acceleration voltage of $5 \mathrm{kV}$. Owing to fracture of cut surfaces and bending of the electrodes with the QSE layers during stacking at edges, short circuits sometimes occurred. Hence, to avoid the occurrence of the short circuits, a $16-\mu \mathrm{m}$ thick three layer separator, comprised of polyethylene, polypropylene and polyethylene, (UPZ520, Ube Maxell Co., Ltd.) was placed between the QSE layers of the positive and the negative electrodes, as in a structure schematically illustrated in Fig. 1.

The bi-layer positive electrode with the QSE and the negative electrode were cut into $146 \mathrm{~mm} \times 76 \mathrm{~mm}$ and $150 \mathrm{~mm} \times 80 \mathrm{~mm}$, respectively. Then, 38 negative electrodes and 37 positive electrodes were stacked together with the folded tabs and placed in a joint bag, which was prepared using an aluminum laminate in a manner described in Fig. 1(e) with a battery storage space of $160 \mathrm{~mm} \times$ $83 \mathrm{~mm} \times 16.5 \mathrm{~mm}$, as schematically illustrated in Fig. 1(a). Note that our bezel-less LIB has a height of $16.5 \mathrm{~mm}$, which is beyond the limit of the press drawing of the conventional aluminum laminates. This is one of the energy density enhancement factors of our bezelless LIB.
A solvate ionic liquid, an equimolar complex of tetraethylene glycol dimethyl ether (G4, $\geq 99 \%$, Merck KGaA) and lithium bis(trifluoromethanesulfonyl)amide (LiTFSA, 99.5\%, Kishida Chemical Co., Ltd., Li(G4)TFSA, ${ }^{12,13}$ was used for the liquid phase of the QSE). Then, to enhance lithium-ion transport during battery operation while maintaining the ignition point of the mixed liquid, propylene carbonate (PC, 99.5\%, Kishida Chemical Co., Ltd.) was mixed together. ${ }^{6}$ On the basis of systematic investigations of viscosity, ion conductivity, self-diffusion coefficient and battery performance as a function of PC concentration, we determined the optimal mixing ratio of $\mathrm{Li}(\mathrm{G} 4) \mathrm{TFSA}-44.5 \mathrm{wt} \% \mathrm{PC}$ (with the ignition point of $415 \mathrm{~K}$, as opposed to $293-303 \mathrm{~K}$ of the conventional organic liquid electrolyte ${ }^{14}$ ). For establishing a stable solid electrolyte interphase (SEI), $3 \mathrm{wt} \%$ of vinylene carbonate (VC, 99.5\%, Kishida Chemical Co., Ltd.) was introduced as a primary additive. Then, for inhibition of corrosion of the aluminum positive electrode current collector by the use of LiTFSA, ${ }^{15} 2.5 \mathrm{wt} \%$ of tetrabuthyl ammonium hexafluorophosphate $\left(\mathrm{TBAPF}_{6},>98 \%\right.$, Tokyo Chemical Industry Co., Ltd.) was also introduced as a secondary additive. The details of the liquid composition optimization are described in Ref. 6. The resultant mixed liquid was injected into a bezel-less LIB, evacuated, sealed and left for 16 hours for sufficient impregnation. The battery assembly was carried out in a dry room, where a dew point was kept at $-30^{\circ} \mathrm{C}$.

To inhibit gas evolution by a formation of stable solid-electrolyte interphase (SEI) at the graphite surface and to enhance coulombic efficiency at the initial cycle, ${ }^{6}$ the charge was started at $0.005 \mathrm{C}$ for $10 \mathrm{hr}$. Subsequently, the charge rate (c-rate) was increased to $0.05 \mathrm{C}$ ( $1 \mathrm{C}$ is equal to $36 \mathrm{~A}$, corresponding to $160 \mathrm{mAhg}^{-1}$ where the current was normalized by the weight of the positive electrode active material) until the voltage reached $4.2 \mathrm{~V}$. The voltage was kept at $4.2 \mathrm{~V}$ until the current decreased to $0.005 \mathrm{C}$. Discharge was carried out at $0.05 \mathrm{C}, 0.1 \mathrm{C}, 0.2 \mathrm{C}$, and $0.5 \mathrm{C}$ until the voltage decreased to $2.7 \mathrm{~V}$. The volumetric power density was evaluated by the directcurrent resistance (DCR) technique. The state-of-charge (SOC) of 
the bezel-less LIB was kept at 50\%, and then the LIB was discharged at $0.1 \mathrm{C}, 0.2 \mathrm{C}$, and $0.5 \mathrm{C}$ for 10 seconds. The volumetric power density was estimated from the relationship between the voltage drop and current density (or c-rate).

The cycle life of the bezel-less LIB was also evaluated. The discharge capacity at $0.05 \mathrm{C}$ was recorded with an interval of 20 cycles at $0.2 \mathrm{C}$. The retention ratio of the discharge capacity was defined as a ratio of the discharge capacity to the initial discharge capacity at $0.05 \mathrm{C}$.

In this study, the overcharge test and the collapse test were carried out to evaluate the safety of the bezel-less LIB. For the overcharge test, the bezel-less LIB was fully charged at $4.2 \mathrm{~V}$ and then, the cell was further charged at $1 \mathrm{C}$ until voltage exceeded $5 \mathrm{~V}$ (120\% of the SOC) or the SOC exceeded $130 \%$ (both are safety criteria determined by IEC62660-3). A thermocouple was placed on the LIB, and then the LIB temperature was monitored during the overcharge test. The fully charged bezel-less LIB was used for the collapse test. The cell was fixed on a holder, and then the LIB was collapsed by a semi-circular ball with a rate of $0.1 \mathrm{~mm} \mathrm{sec}^{-1}$. A thermocouple was attached onto the LIB surface, and the LIB temperature was recorded during the collapse test.

\section{Results \& Discussion}

In our LIB configuration, the thickness of the QSE layer is one of the key factors determining the safety of LIB. We reported that a 20$\mu \mathrm{m}$ thick QSE layers on both the positive and negative electrodes ( $40 \mu \mathrm{m}$ in total) can inhibit short circuits via a metallic nail, thus minimizing the generation of the joule heat. In addition, the high ignition point of the liquid phase $(415 \mathrm{~K})$ contributes to inhibition of firing triggered by the joule heat generation. ${ }^{16}$ The QSE layer should be thin as it does not contribute to the energy storage and is one of the factors of the internal resistance increase. When the QSE layer is too thin, a short circuit can easily happen, compromising the safety of the battery. Considering the above, we decided to form a $10-\mu \mathrm{m}$ thick QSE layer. By optimizing the QSE and slurry compositions and coating conditions, we succeeded in placing a uniform $10-\mu \mathrm{m}$ thick QSE layer only on the positive electrode layer, as shown in the cross-sectional SEM image in Fig. 2. The volume ratio of $\mathrm{SiO}_{2}$, $\mathrm{P}(\mathrm{VdF}-\mathrm{HFP})$ and void was 45.2:6.8:48, estimated from the QSE slurry composition and the size of the coated QSE layer.

The bezel-less LIB assembled in this study demonstrated repeated operation with high capacity and high coulombic efficiency, as can be seen in the charge-discharge profiles in Fig. 3(a). The bezel-less LIB exhibited an initial charge capacity of $43.7 \mathrm{Ah}$ and a discharge capacity of $36.6 \mathrm{Ah}$ (with coulombic efficiency of $83.7 \%$ ). At the average voltage of $3.6 \mathrm{~V}$ during the discharge, our bezel-less LIB has the energy of $132 \mathrm{Wh}$. From the bezel-less LIB energy and geometry, a volumetric energy density was calculated to be $600 \mathrm{Wh} \mathrm{L}^{-1}$ $\left(256 \mathrm{Wh} \mathrm{kg}^{-1}\right)$. The bezel-less LIB design can eliminate extra volumes for sealing and accumulation of current collectors, achieving $16 \%$ of volume reduction, compared to the conventional aluminum laminates, as schematically shown in Figs. 1(c) and (d) and Fig. S1. This surely contributes to the enhanced energy density. Another advantage of the bezel-less LIB concept is that it does not have thickness restrictions. This is different from a conventional press drawing that have a limitation on thickness to avoid a fracture of aluminum. The spaces for laminates of individual cells in the LIB pack can be reduced, further enhancing energy density of the LIB pack for the large-scale applications such as EVs and stationary uses which require a number of LIBs and laminates.

The bezel-less LIB retained high discharge capacity of $27.0 \mathrm{Ah}$ at $0.5 \mathrm{C}$, as the discharge profiles shown in Fig. 3(b). As seen in the figure, the discharge capacity monotonically decreased as the c-rate increased. The bezel-less LIB employed a $10-\mu \mathrm{m}$ QSE, the resistance from the ion transport in thick electrode layers (both

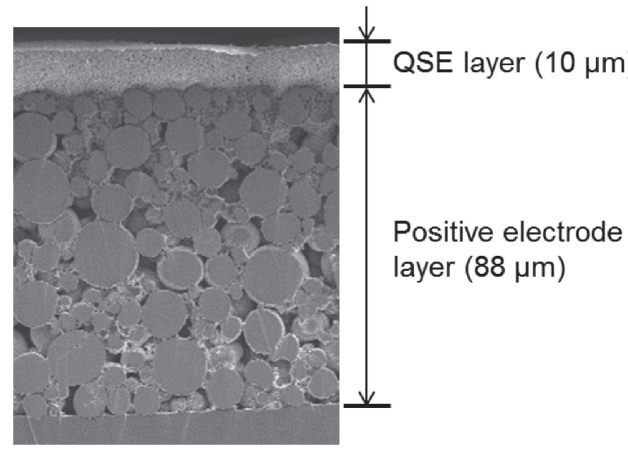

Figure 2. Cross-sectional FE-SEM image of the bi-layer QSE and positive electrode.
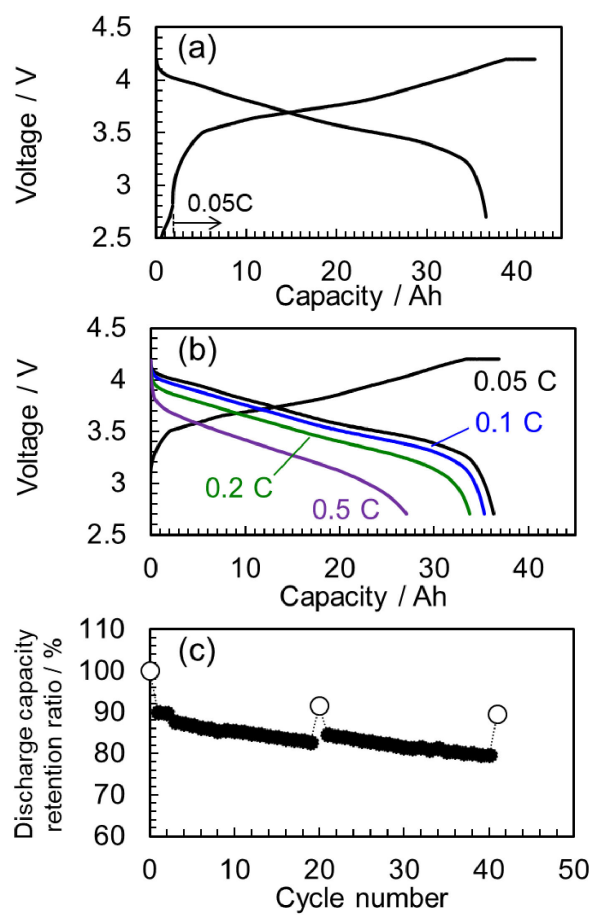

Figure 3. Performance evaluation results of the bezel-less LIB: (a) Initial charge-discharge profile. At the beginning of the initial charge, $0.005 \mathrm{C}$ charge was carried out for $10 \mathrm{~h}$ to establish a stable SEI. Subsequently, $0.05 \mathrm{C}$ charge was carried out up to $4.2 \mathrm{~V}$, and voltage was kept at $4.2 \mathrm{~V}$ until the charge current decreased to $0.005 \mathrm{C}$. $0.05 \mathrm{C}$ discharge was carried out down to $2.7 \mathrm{~V}$. (b) discharge profiles at $0.05 \mathrm{C}, 0.1 \mathrm{C}, 0.2 \mathrm{C}$, and $0.5 \mathrm{C}$, and (c) discharge capacity retention ratio (to the initial discharge capacity) as a function of cycle number. Open and closed circles show discharge capacities at $0.05 \mathrm{C}$ and $0.2 \mathrm{C}$, respectively.

positive and negative electrode layers are $88-\mu \mathrm{m}$ thick) can increase the internal resistance. Hence, further exploration of the liquid phase used for the QSE is required for enhancing the high rate capability in future studies. From the DCR measurement, the output power was quantified. The linear relationship between the voltage drop and current density was confirmed by the DCR measurement, and then the power density was estimated to be $1160 \mathrm{~W} \mathrm{~L}^{-1}$ at the SOC of $50 \%$. As shown in Fig. 3(c), the 41 st discharge capacity retention ratio was as high as $90 \%$, and an expansion of the bezel-less LIB was not obvious after the cycle test.

The safety of the bezel-less LIB was investigated by the overcharge and collapse tests. The bezel-less LIB passed the overcharge test, i.e. inhibition of thermal runaway at voltage of $120 \%(5.0 \mathrm{~V}$ in our LIB) or the SOC of $130 \%$. Figure 4 shows 


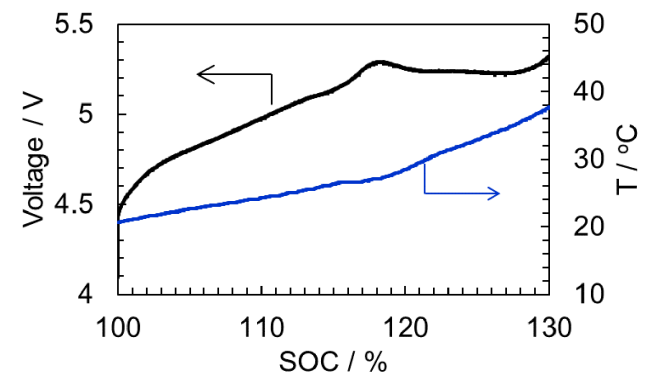

Figure 4. Overcharge test result of the bezel-less LIB: Voltage and LIB temperature as a function of SOC.
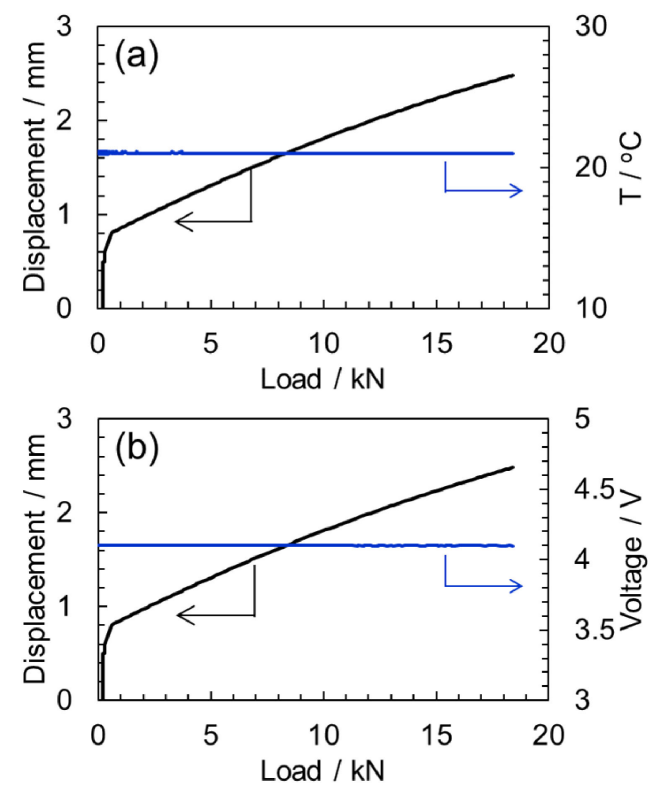

Figure 5. Collapse test result of the bezel-less LIB: (a) Displacement and LIB temperature, and (b) displacement and voltage as functions of applied load.

voltage and temperature of the bezel-less LIB temperature as a function of SOC. At the beginning of the overcharge test, the LIB voltage increased monotonically and reached $5.0 \mathrm{~V}$ at the SOC of $110 \%$. Then, the LIB voltage increased to $5.3 \mathrm{~V}$ at the SOC of $130 \%$. During the overcharge test, the LIB temperature was monotonically increasing, and the temperature increase was less than $20^{\circ} \mathrm{C}$ at the SOC of $130 \%$ (temperature at the beginning was $23^{\circ} \mathrm{C}$ ). A possible explanation of the inhibition of voltage increase would be the instability of the QSE at the positive electrode surface. This means, the applied current at the SOC of over $110 \%$ is likely consumed for the electrochemical decomposition reaction of the QSE and not for the lithium storage. Further investigation of the QSE stability at the electrode surface is necessary to look deep inside the safety mechanism under overcharge conditions.

Our bezel-less LIB also passed the collapse test, as shown in Fig. 5. Figure 5(a) shows displacement and temperature of the bezel-less LIB as a function of applied load. The relationship between displacement and voltage of the bezel-less LIB is shown in Fig. 5(b). The cell temperature did not change (remained constant at $21^{\circ} \mathrm{C}$ during the test), and thermal runaway was hindered at the applied loads of $6 \mathrm{kN}$ (corresponding to 1000 times of the LIB weight) and $18 \mathrm{kN}$ (deformation of over 15\%). This is considered to be due to the existence of the QSE layer. The QSE layer contains high concentration of oxides, which enhanced the hardness and contributed to the inhibition of a contact between the positive and negative electrodes during the collapse of LIB.
As demonstrated in this communication, the novel bezel-less concept enhances the energy density by minimizing the volume of the bezel part of the LIBs. High safety of the bezel-less LIB was successfully demonstrated via the overcharge and collapse test. Development of the QSE sheet that guarantees the insulation at the edge of electrode layers and allows for the LIB assembly without separator would be fruitful for further enhancing an energy density. A combined use of the QSE and the bezel-less concept for the LIB assembly can contribute to enhancing the energy density of the LIB packs used for large-scale applications, including EVs and stationary uses.

\section{Conclusions}

In this study, we developed a high capacity, high energy density and high power bezel-less LIB with the QSE. The bezel-less LIB demonstrated a capacity of $132 \mathrm{Wh}$, an energy density of $600 \mathrm{Wh} \mathrm{L}^{-1}\left(256 \mathrm{Wh} \mathrm{kg}^{-1}\right)$, and an output power of $1160 \mathrm{~W} \mathrm{~L}^{-1}$. The bezel-less LIB enabled stable and repeated operation. The 41st discharge capacity retention ratio recorded $90 \%$. In addition, the bezel-less LIB passed the overcharge and collapse tests, based on the IEC62660-3 standard. These results suggest that a combined use of the bezel-less concept and the QSE may enhance the energy density of the LIB and the LIB pack for large-scale applications such as EVs and stationary uses.

\section{Supporting Information}

The Supporting Information is available on the website at DOI: https://doi.org/10.5796/electrochemistry.19-00076.

\section{Acknowledgment}

Part of this study was supported by Innovative Science and Technology Initiative for Security, Acquisition, Technology \& Logistics Agency (ATLA), Japan.

\section{References}

1. P. K. Nayak, E. M. Erickson, F. Schipper, T. R. Penki, N. Munichandraiah, P. Adelhelm, H. Sclar, F. Amalraj, B. Markovsky, and D. Aurbach, Adv. Energy Mater, 8, 1702397 (2018).

2. Q. Pang, X. Liang, C. Y. Kwok, and L. F. Nazar, Nat. Energy, 1, 16132 (2016).

3. D. M. Piper, T. Evans, S. Xu, S. C. Kim, S. S. Han, K. L. Liu, K. H. Oh, R. Yang, and S.-H. Lee, Adv. Mater, 28, 188 (2016).

4. D. Aurbach, E. Zinigrad, Y. Cohen, and H. Teller, Solid State Ionics, 148, 405 (2002).

5. D. H. Doughty and E. P. Roth, Electrochem. Soc. Interface, 21, 37 (2012).

6. A. Unemoto, S. Ueda, E. Seki, M. Oda, J. Kawaji, T. Okumura, Y. Gambe, and I. Honma, Electrochemistry, 87, 100 (2019).

7. T. Tamura, K. Yoshida, T. Hashida, M. Tsuchiya, M. Nakamura, Y. Kazue, N. Tachikawa, K. Dokko, and M. Watanabe, Chem. Lett., 39, 753 (2010).

8. K. Yoshida, M. Nakamura, Y. Kazue, N. Tachikawa, S. Tsuzuki, S. Seki, K. Dokko, and M. Watanabe, J. Am. Chem. Soc., 133, 13121 (2011).

9. H. Ogawa, A. Unemoto, and I. Honma, Electrochemistry, 80, 765 (2012).

10. A. Unemoto, T. Matsuo, H. Ogawa, Y. Gambe, and I. Honma, J. Power Sources, 244, 354 (2013).

11. G. Robertson, M. Czerwinski, P. Baudisch, B. Meyers, D. Robbins, G. Smith, and D. Tan, IEEE Comput. Graph., 25, 44 (2005).

12. T. Tamura, K. Yoshida, T. Hashida, M. Tsuchiya, M. Nakamura, Y. Kazue, N. Tachikawa, K. Dokko, and M. Watanabe, Chem. Lett., 39, 753 (2010).

13. K. Yoshida, M. Nakamura, Y. Kazue, N. Tachikawa, S. Tsuzuki, S. Seki, K. Dokko, and M. Watanabe, J. Am. Chem. Soc., 133, 13121 (2011).

14. F. Chretien, J. Jones, C. Damas, D. Lemordant, P. Willimann, and M. Anouti, J. Power Sources, 248, 969 (2014).

15. L. J. Krause, W. Lamanna, J. Summerfield, M. Engle, G. Korba, R. Koch, and R. Atanasoski, J. Power Sources, 68, 320 (1997).

16. C.-H. Doh, D.-H. Kim, H.-S. Kim, H.-M. Shin, Y.-D. Jeong, S.-I. Moon, B.-S. Jun, S. W. Eom, H.-S. Kim, K.-W. Kim, D.-H. Oh, and A. Veluchamy, J. Power Sources, 175, 881 (2008). 